\title{
Utilization of Reproductive Health Services among Youths in Owerri, Southeastern Nigeria
}

\author{
Onyeneke, J.U. ${ }^{1}$, Ibebuike, J. ${ }^{2}$, Vincent, C.C.N. ${ }^{2}$, Udo-Inyang, F.O. ${ }^{1}$ \\ ${ }^{1}$ Department of Public Health Nursing, Imo State College of Nursing Sciences, Orlu, Imo State, Nigeria \\ ${ }^{2}$ Department of Nursing Sciences, Imo State University, Owerri, Imo State, Nigeria
}

Corresponding Author: Onyeneke, J.U.

\section{ABSTRACT}

Youths are faced with immense reproductive health problems and they have limited access to reproductive health services. This study was carried out to investigate the utilization of reproductive health services among youths in Owerri, Southeastern Nigeria. The study was a descriptive cross sectional study and the multistage sampling technique was adopted to select samples for the study. A well-structured questionnaire was used to interview the subjects and obtain data for the study which was uploaded into the SPSS version 21 software and the Chi-square was used to test for association at $5 \%$ level of significance. A total of 424 people were studied comprising of $276(65.1 \%)$ males and 148 (34.9\%) females. Results showed that only $106(25 \%)$ showing good knowledge of reproductive health services while $318(75 \%)$ showed poor knowledge. Among the 148 that have used reproductive services, 56.8\% responded that they seek reproductive services in the home of a health worker, $29.1 \%$ seek reproductive health services through public health facilities such as health centers, clinic or NGO, and $14.2 \%$ obtain their reproductive health services through drug shops such as a pharmacy or chemist. SPSS analysis using the Chi-square showed that the male gender showed poorer knowledge of RHS than the female gender but gender was not found to be significant $\quad\left(p=0.098, \quad \chi^{2}=1.993\right)$. Other significant socio-demographic factors include marital status $\left(\mathrm{p}=0.0001, \chi^{2}=46.29\right)$, living pattern $\left(p=0.005, \chi^{2}=6.93\right)$ and education $\left(\mathrm{p}=0.0001, \chi^{2}=17.8\right)$. In conclusion, the study showed that the knowledge and the level of utilization RHS is still low among youths in the study area. It was recommended that stakeholders sensitize the public on the importance of youth reproductive health services and strengthen the idea of youth friendly reproductive health services.

Key Words: Youth, Utilization, Knowledge, Reproductive Health Services, Youth Friendly Services

\section{INTRODUCTION}

Youths represent a tremendously valuable asset to the society therefore working with them to make a healthy transition to adulthood is critical to the world's development now and in the future. [1] Though youths are faced with immense reproductive health problems, they have limited access to reproductive health services and information that are specially designed to meet their needs. Available reproductive health services are adult centered, thus, they are less accessible to youths. Factors like non-youth friendliness of the existing service outlet and the limited economic and physical access this group of the society have are among other factors contributing to their low access and utilization of existing services. ${ }^{[2]}$ Recent estimates indicate that $17.0 \%$ of the global population, $20.0 \%$ of sub-Saharan Africa and $36.5 \%$ of Nigerians population is composed of youth aged 15-24 years. ${ }^{[2]}$ About 1.8 million of this age group are living in contemporary issues. They constitute the developmental "cream of the crop" for the future of the world and possess 
an intrinsic human right, a necessity that must be accorded and duly satisfied. ${ }^{[2]}$

There exists no worldwide definition of the term "youth", this phase of life differs from the period of pregnancy and those of infancy which have definite time frame and age assortments and so, the meaning of a youth varies according to individuals, programmes and organization. [3] Young people can be defined as those aged 10-24 years; and this group combines adolescents (aged 10-19 years) and youths (aged 15-24 years). ${ }^{[4]}$ Youth reproductive health is a state of complete physical, mental and social well-being and not merely the absence of disease or infirmity in all matters concerning to the reproductive health of persons between the ages of 15 and 24. The general realization of youth reproductive health tends to depend on the level of awareness of young people to the available reproductive health services, the nature of provision of these services and the utilization of these services by youths. ${ }^{[5]}$

Reproductive health is central to human identity and imperative for health and well-being. $\mathrm{Uka}^{[6]}$ stated that youth reproductive health is critical due to the gregarious sexual activities, which predispose them to negative sexual and reproductive health outcomes such as Sexually Transmitted Infections (STIs) including Human Immunodeficiency Virus (HIV) Acquired Immune Deficiency Syndrome (AIDS), unwanted pregnancies, unsafe abortion and death. Such negative sexual and reproductive health outcomes have economic, social, and health consequences that affect young people throughout their lives, as well as their families, countries, and the global community at large. ${ }^{[1,6]}$ Implicit in the definition are the rights of men and women to be informed and have access to safe, effective, affordable and acceptable methods of family planning of their choice. The right of access to other methods of their choice for regulation of fertility, which are not against the law, and the right to access appropriate health-care services that will enable women to go safely through pregnancy and childbirth and providing couples with the best chance of having a healthy infant are not left out in the definition. Another dimension to reproductive health is sexual health, the purpose of which is the enhancement of life and personal relations, and not merely counseling and care related to reproduction and sexually transmitted diseases. ${ }^{[7]}$

Contemporarily and for obvious reasons, youths have the right to live healthy lives. "Reproductive health is not just about sex, rather it constitute part of a holistic health programme which begins from early age teaching, clarification of values and understating the anatomy and physiology of their bodies". [8] This tutelage continues throughout the adolescence and youthful periods to enable young people have access to the various methods of contraception that is safe and acceptable; and appropriate healthcare services that will make them stay healthy. ${ }^{[8]}$ However, for many African youths, the transition through youthful age to adulthood continues to be fraught with several challenges and difficulties. These include high rates of poverty, illiteracy, unemployment and underemployment, violence, sexual coercion and exploitation, substance abuse and other deviant social behaviors. Coupled with high rates of judgmental values by adults and negative societal/cultural attitudes which deny youths access to appropriate information and services especially on sexual and reproductive health, it is not surprising that African youths currently have some of the highest rates of HIV/AIDS in the world. ${ }^{[1]}$

In Nigeria, one third of the total population of 184.6 million ${ }^{[9]}$ is between the ages of 10 and 24 years. This sizable share of the population makes the youth integral to the country's social, political and economic development. Accessibility, communication, cultural effectiveness and empathy are all attributes of quality care to all age groups. But studies regarding young people's perspectives on RHS in Nigeria have indicated that youths trying to seek for 
RHS information are persistently engulfed in hurdles which may be related to provider attitudes, political instability, and culture. [10] The type of sexual and reproductive health services (SRHS) intended to be provided at youth friendly service (YFS) outlet varies and involves service delivery points both within and outside the public health system. However, with the establishment of appropriate referral linkages between the different service outlets, it would be possible to ensure that youths get a combination of different promotive, preventive, curative and rehabilitative services rendered at the different service outlets. ${ }^{[11]}$

The different types of youth friendly SRHS youths need to get should include information and counseling on Reproductive and Sexual Health issues and sexuality, promotion of health sexual behaviors through various methods including peer education, family planning information, counseling and methods including emergency contraceptive methods, condom promotion and provision, testing services: pregnancy, HIV testing and counseling (HCT), management of sexually transmitted infections. Antenatal care, Delivery Services, Postnatal Care and prevention of mother to child transmission (PMTCT), abortion and Post abortion care, appropriate referral linkage between facilities at different. Lack of youth friendly health services may be due to the hostile attitude of health care providers. Some people feel that health care providers scare youth from accessing health care facilities. Due to the unfriendly attitude of health care providers, many youth are now engaging in all forms of unorthodox practices to solve their health care needs. Hence, this study intends to explore the utilization of youth reproductive health services in Owerri, Southeastern Nigeria.

\section{MATERIALS AND METHODS}

The study was a descriptive cross sectional study to investigate the type of provision of reproductive health services to youths in Southeastern, Nigeria. The multistage sampling technique was adopted to select samples for the study. A wellstructured questionnaire was used to interview the subjects and obtain data for the study. All subjects used for this study gave an informed consent to be part of the study. Data was uploaded into the SPSS version 21 software and the Chi-square was used to test for association at 5\% level of significance.

\section{RESULTS}

Table 1: Socio demographic Characteristics of the Respondents

\begin{tabular}{|c|c|c|}
\hline Variable & $\mathbf{n}$ & $\%$ \\
\hline \multicolumn{3}{|l|}{ Gender } \\
\hline Male & 276 & 65.1 \\
\hline Female & 148 & 34.9 \\
\hline Total & 424 & 100.0 \\
\hline \multicolumn{3}{|l|}{ Age } \\
\hline $15-19$ & 129 & 30.4 \\
\hline $20-24$ & 295 & 69.6 \\
\hline Total & 424 & 100.0 \\
\hline \multicolumn{3}{|l|}{ Religion } \\
\hline Christianity & 355 & 83.7 \\
\hline Islam & 58 & 13.7 \\
\hline Others & 11 & 2.6 \\
\hline Total & 424 & 100.0 \\
\hline \multicolumn{3}{|l|}{ Marital Status } \\
\hline Single & 294 & 69.3 \\
\hline Married & 119 & 28.1 \\
\hline Others & 11 & 2.6 \\
\hline Total & 424 & 100.0 \\
\hline \multicolumn{3}{|c|}{ Person Living With: } \\
\hline Alone & 127 & 30.0 \\
\hline With Parents & 297 & 70.0 \\
\hline Total & 424 & 100.0 \\
\hline \multicolumn{3}{|c|}{ Education Level } \\
\hline Non formal & 42 & 9.9 \\
\hline Primary & 42 & 9.9 \\
\hline Secondary & 128 & 30.2 \\
\hline Tertiary & 212 & 50.0 \\
\hline Total & 424 & 100.0 \\
\hline \multicolumn{3}{|l|}{ Occupation } \\
\hline Schooling & 256 & 60.4 \\
\hline Trading & 126 & 29.7 \\
\hline Public Servant & 21 & 5.0 \\
\hline Others & 21 & 5.0 \\
\hline Total & 424 & 100.0 \\
\hline
\end{tabular}

The socio - demographic characteristics of the youths who participated in the study was presented on Table 1 . The table shows that a total of 424 people were studied comprising of 276 (65.1\%) males and 148 (34.9\%) females. Majority of the participants $(295 ; 69.6 \%)$ were between $20-24$ years of age and the remaining 129 (30.4\%) fell within 15-19 years. The youths were predominantly 
Christians $(355 ; 83.7 \%)$, some were of Islam $(58 ; 13.7 \%)$ and just $11(2.6 \%)$ practiced other religion such as traditional religion. Many of the participants (294; $69.3 \%)$ were single, $119(28.1 \%)$ were married while $11(2.6 \%)$ were separated. A total of $127(30 \%)$ live alone while 297 $(70 \%)$ responded that they live with their parents. Their level of education was such that half of them $(212 ; 50 \%)$ studied up to tertiary education level, 128 (30.2\%) studied up to secondary education level while 42 (9.9\%) each respectively studied up to primary education and without formal education. In terms of what they do for a living, a total of $256(60 \%)$ were schooling, $126(29.7 \%)$ engage in trading activities, 21 (5\%) were public servants and another 21 $(5 \%)$ were on other different occupations including farming, artisans, applicants, etc.

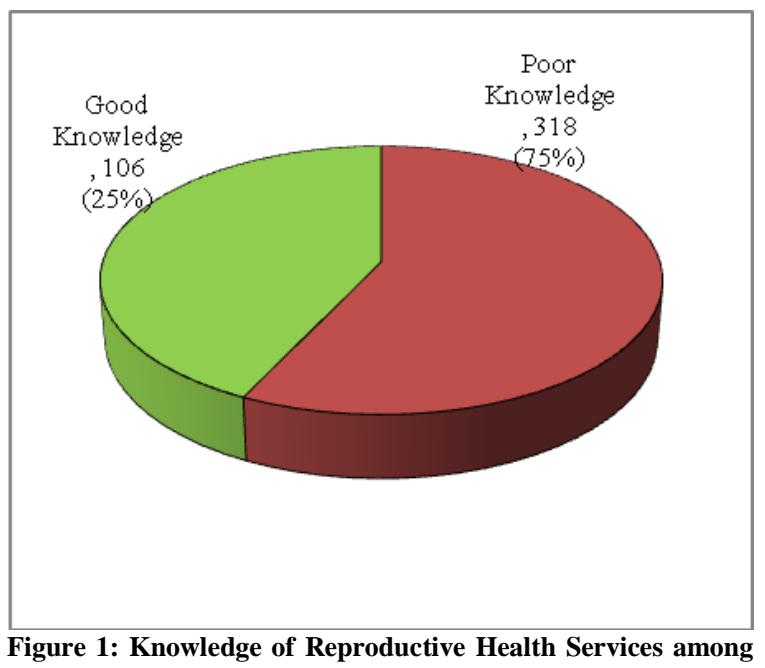
Youths

Figure 1 represents the level of knowledge of reproductive health services among youths. The figure showed that the youths do not possess adequate knowledge of reproductive health services with only $106(25 \%)$ showing good knowledge while a clear majority $(318 ; 75 \%)$ showed poor knowledge. Table 2 showed that among the 148 that have used reproductive services, more than half of them $(56.8 \%)$ responded that they seek reproductive services in the home of a health worker, $29.1 \%$ seek reproductive health services through public health facilities such as health centers, clinic or NGO, and $14.2 \%$ obtain their reproductive health services through drug shops such as a pharmacy or chemist. Some of the most obvious reasons why they obtained reproductive health services through areas mentioned include reduced waiting service time (42.6\%), affordability of services (42.6\%) and confidentiality $(28.4 \%)$. Among the reproductive health services used were for family planning services and the prevention and treatment of STIs/STDs. In terms of family planning, the most used reproductive health services is the oral pills $(84 ; 56.8 \%)$, followed by the injectable $(22 ; 14.9 \%)$ and the barrier method $(21 ; 14.2 \%)$. On the other hand, the most used reproductive health services for prevention and treatment of STIs/STDs include counseling on the ABC of prevention of STIs/HIV (Abstinence, being faithful and condom use) (43; 29.1\%), followed by the HIV counseling and testing and treatment for HIV/AIDs at $14.2 \%$ each.

Table 3 showed that among the youths that do not utilize reproductive health services, a total of 128 (46.4\%) reported that fear of being seen by parents at the health facility was the most reason for such none use of the reproductive health services. That was followed by feeling of shame to be seen and shyness $(84 ; 30.4 \%)$ and lack of awareness $(64 ; 23.2 \%)$. Most youths were of the view that the RHS are not for them, and they fear that the health workers will be biased, unfriendly and hostile, as well as several other perceptions that bring barriers to the utilization of reproductive health services. In consideration to some of these reasons as shown in on Table 4, the average scores were quite high in all the items assessed with none of the mean values being below 2.5. However, the mean score was highest on being afraid of the hospital procedure with 3.3 points out of $4(82.5 \%)$ with 233 $(55.0 \%)$ of the respondents who strongly agreed to that view. The mean score was only lowest on when they were asked if it the use of reproductive services was against their religion $(2.5 ; 62.5 \%)$. While up to 
Onyeneke, J.U. et.al. Utilization of reproductive health services among youths in Owerri, Southeastern Nigeria.

$60.1 \%$ agreed that reproductive health them strongly agreed to it. services were against their religion, none of

Table 2: Characteristics for usage of reproductive health services among youths $(n=148)$

\begin{tabular}{|l|l|l|}
\hline Where they seek the reproductive health services & $\mathbf{n}$ & $\boldsymbol{\%}$ \\
\hline Public health facility(Health Centre, clinic or NGO) & 43 & 29.1 \\
\hline In the home of a health worker & 84 & 56.8 \\
\hline Pharmacy//Chemist & 21 & 14.2 \\
\hline Road side vendor (Patent medicine shop? & 0 & 0.0 \\
\hline Traditional/healing homes & 0 & 0.0 \\
\hline Reason(s) for using services in the chosen places & & \\
\hline Confidentiality & 42 & 28.4 \\
\hline Place is secluded & 22 & 14.9 \\
\hline Short waiting time & 63 & 42.6 \\
\hline The services are affordable/free & 63 & 42.6 \\
\hline Convenient opening hours & 0 & 0.0 \\
\hline Facility is close & 21 & 14.2 \\
\hline Facility is always open & 0 & 0.0 \\
\hline The workers are friendly & 0 & 0.0 \\
\hline Reproductive services Used: Family planning services & & \\
\hline Oral pills & 84 & 56.8 \\
\hline Injectable & 22 & 14.9 \\
\hline IUD & 0 & 0.0 \\
\hline Barrier method (eg condom) & 21 & 14.2 \\
\hline Implants & 0 & 0.0 \\
\hline Natural method(eg, calendar, body sign etc) & 0 & 0.0 \\
\hline Reproductive services Used: Prevention and treatment of STIs/STDs & 0 & 0.0 \\
\hline Counseling on the ABC of prevention of STIs/HIV (Abstinence, being faithful and condom use) & 43 & 29.1 \\
\hline HIV counseling and testing. & 21 & 14.2 \\
\hline Treatment for HIV/AIDs & 21 & 14.2 \\
\hline Treatment for genital ulcers & 0 & 0.0 \\
\hline Treatment for genital discharges & 0 & 0.0 \\
\hline Services for infertility and other reproductive health problems & 0 & 0.0 \\
\hline Prevention and treatment of cancers & 0 & 0.0 \\
\hline Counseling on how to do breast self-examination & 0 & 0.0 \\
\hline Cervical screening & 0 & 0.0 \\
\hline Services during pregnancy & 0 & 0.0 \\
\hline Services during child birth or labor & 12 & 8.1 \\
\hline Services after delivery (post natal) & 0 & 0.0 \\
\hline Services for rape or other forms of sexual violence & 0 & 0.0 \\
\hline Post abortion services. & 0 & 0.0 \\
\hline & \\
\hline
\end{tabular}

Table 3: Reasons for not using Reproductive Health Services $(n=276)$

\begin{tabular}{|l|l|l|}
\hline Reasons for not using RHS & $\mathbf{n}$ & $\mathbf{\%}$ \\
\hline Feeling of shame to be seen and Shyness & 84 & 30.4 \\
\hline Fear of being seen by parents at the health facility & 128 & 46.4 \\
\hline Lack of awareness & 64 & 23.2 \\
\hline Fear of privacy & 22 & 8.0 \\
\hline Lack of confidentiality & 21 & 7.6 \\
\hline
\end{tabular}

Table 4: Youth Perspectives on Barriers to Reproductive Health Services Utilization

\begin{tabular}{|c|c|c|c|c|c|c|}
\hline Reasons for not using reproductive health services & $\begin{array}{l}\text { Strongly } \\
\text { Agree } \\
\text { n }(\%)\end{array}$ & $\begin{array}{l}\text { Agree } \\
\text { n }(\%)\end{array}$ & $\begin{array}{l}\text { Disagree } \\
\text { n }(\%)\end{array}$ & $\begin{array}{l}\text { Strongly } \\
\text { Disagree } \\
\text { n }(\%)\end{array}$ & Mean & $\begin{array}{l}\text { Std. } \\
\text { dev. }\end{array}$ \\
\hline The services are not for the youths & $233(55.0)$ & $64(15.1)$ & $64(15.1)$ & $63(14.9)$ & 3.1 & 1.1 \\
\hline $\begin{array}{l}\text { Fear that the health worker will be biased, unfriendly and } \\
\text { hostile }\end{array}$ & $43(10.1)$ & $317(74.8)$ & $64(15.1)$ & - & 3.0 & 0.5 \\
\hline Afraid of hospital procedures & $233(55.0)$ & $84(19.8)$ & $107(25.2)$ & - & 3.3 & 0.8 \\
\hline Afraid of the side effects of contraceptives & $105(24.8)$ & $265(60.1)$ & $64(15.1)$ & - & 3.1 & 0.6 \\
\hline Afraid, that the workers will not keep any secret & $190(44.8)$ & $84(19.8)$ & $106(25.0)$ & $44(10.4)$ & 3.0 & 1.1 \\
\hline Not satisfied with the treatment by the health care providers & $191(45.0)$ & $127(30.0)$ & $106(25.0)$ & - & 3.2 & 0.8 \\
\hline Afraid of the unforeseen complications & $190(44.8)$ & $148(34.9)$ & $86(20.3)$ & - & 3.2 & 0.8 \\
\hline $\begin{array}{l}\text { Afraid that parents will get to know about visits made to the } \\
\text { hospital/clinic/health center }\end{array}$ & $169(39.9)$ & $128(30.2)$ & $64(15.1)$ & $63(14.9)$ & 3.0 & 1.1 \\
\hline Ashamed of going to the hospital & $234(55.2)$ & $63(14.9$ & $64(15.1)$ & $63(14.9)$ & 3.1 & 1.1 \\
\hline It is against my religious belief & & $255(60.1)$ & $106(25.0)$ & $63(14.9)$ & 2.5 & 0.7 \\
\hline The operation hours are not convenient & $234(55.2)$ & $42(9.9)$ & $127(30.0)$ & $21(5.0)$ & 3.2 & 1.0 \\
\hline High cost of Services & $63(14.9)$ & $276(65.1)$ & $85(20.0)$ & - & 2.9 & 0.6 \\
\hline
\end{tabular}




\begin{tabular}{|c|c|c|c|c|c|c|c|}
\hline \multirow[b]{2}{*}{ Socio-demographic } & \multicolumn{2}{|c|}{ Poor knowledge } & \multicolumn{2}{|c|}{ Good knowledge } & \multirow[b]{2}{*}{ Total } & \multirow[b]{2}{*}{ Chi- square $\left(\chi^{2}\right)$} & \multirow[b]{2}{*}{$\mathbf{P}$} \\
\hline & $\mathbf{n}$ & $\%$ & $\mathbf{n}$ & $\%$ & & & \\
\hline \multicolumn{8}{|l|}{ Gender } \\
\hline Male & 213 & 77.2 & 63 & 22.8 & 276 & & \\
\hline Female & 105 & 70.9 & 43 & 29.1 & 148 & & \\
\hline Total & 318 & 75.0 & 106 & 25.0 & 424 & 1.993 & 0.098 \\
\hline \multicolumn{8}{|l|}{ Age (years) } \\
\hline $15-19$ & 106 & 82.2 & 23 & 17.8 & 129 & & \\
\hline $20-24$ & 212 & 71.9 & 83 & 28.1 & 295 & & \\
\hline Total & 318 & 75.0 & 106 & 25.0 & 424 & 5.084 & $0.024^{*}$ \\
\hline \multicolumn{8}{|l|}{ Religion } \\
\hline Christianity & 271 & 76.3 & 84 & 23.7 & 355 & & \\
\hline Islam & 40 & 69.0 & 18 & 31.0 & 58 & & \\
\hline Other (Traditional) & 7 & 63.6 & 4 & 36.4 & 11 & & \\
\hline Total & 318 & 75.0 & 106 & 25.0 & 424 & 2.223 & 0.329 \\
\hline \multicolumn{8}{|l|}{ Marital Status } \\
\hline Single & 247 & 84.0 & 47 & 16.0 & 294 & & \\
\hline Married & 62 & 52.1 & 57 & 47.9 & 119 & & \\
\hline Separated & 9 & 81.8 & 2 & 18.2 & 11 & & \\
\hline Total & 318 & 75.0 & 106 & 25.0 & 424 & 46.29 & $0.0001 *$ \\
\hline \multicolumn{8}{|l|}{ Living Pattern } \\
\hline Living Alone & 106 & 83.5 & 21 & 16.5 & 127 & & \\
\hline Living with Parents & 212 & 71.4 & 85 & 28.6 & 297 & & \\
\hline Total & 318 & 75.0 & 106 & 25.0 & 424 & 6.93 & $0.005^{*}$ \\
\hline \multicolumn{8}{|l|}{ Education Level } \\
\hline Non formal & 39 & 92.9 & 3 & 7.1 & 42 & & \\
\hline Primary & 28 & 66.7 & 14 & 33.3 & 42 & & \\
\hline Secondary & 106 & 82.8 & 22 & 17.2 & 128 & & \\
\hline Tertiary & 145 & 68.4 & 67 & 31.6 & 212 & & \\
\hline Total & 318 & 75.0 & 106 & 25.0 & 424 & 17.8 & $0.0001 *$ \\
\hline \multicolumn{8}{|l|}{ Occupation } \\
\hline Schooling & 194 & 75.8 & 62 & 24.2 & 256 & & \\
\hline Trading & 97 & 77.0 & 29 & 23.0 & 126 & & \\
\hline Public Servant & 15 & 71.4 & 6 & 28.7 & 21 & & \\
\hline Others & 12 & 57.1 & 9 & 42.9 & 21 & & \\
\hline Total & 318 & 75.0 & 106 & 25.0 & 424 & 4.062 & 0.255 \\
\hline
\end{tabular}

The influence of socio-demographic characteristics on the knowledge of reproductive health services was shown on Table 5. Male gender showed poorer knowledge of RHS than the female gender but gender was not found to be significant $\left(p=0.098, \chi^{2}=1.993\right)$. The age was found to be significant $\left(\mathrm{p}=0.024, \chi^{2}=5.084\right)$ and the lesser age group of 15-19 were poorer in knowledge $(82.2 \%)$ than the $20-24$ years $(71.9 \%)$. Other significant sociodemographic factors include marital status $\left(\mathrm{p}=0.0001, \quad \chi^{2}=46.29\right)$, living pattern $\left(\mathrm{p}=0.005, \quad \chi^{2}=6.93\right) \quad$ and education $\left(p=0.0001, \chi^{2}=17.8\right)$. Up to $84 \%$ of the singles showed poorer knowledge compared to $52.1 \%$ among the married. Similarly, $83.5 \%$ of those living alone showed poorer knowledge compared to $71.4 \%$ in those living with their parents. A total of $92.9 \%$ of the respondents without formal education showed poorer knowledge of RHS compared to $68.4 \%$ in the tertiary participants.

\section{DISCUSSION}

This study involving youths between the ages of fifteen and twenty four revealed that their knowledge of reproductive health services was low with only one quarter of the study group showing good knowledge. The poor knowledge found in this study was in line with a report by Uka ${ }^{[6]}$, for which it was maintained that youths lack RHS knowledge and as a result indulge in risky sexual activities. The result is consistent with findings of previous studies ${ }^{[12,13]}$ that parents have been known from various studies and from age immemorial to be the banquet of knowledge, however, when it comes to provision of $\mathrm{RH}$ issues, they become inadequate and seem to act and play ignorant in a bid of having the notion to protect the youth from what they perceive as 
being wrong and indiscipline. In Nepal, findings ${ }^{[11]}$ also showed that parents are not comfortable discussing $\mathrm{RH}$ issues as it is seen as a taboo. These views are not different from the common Nigerian parent, where the youth is left in perpetual inexperience and out of curiosity, the youth engages in discussion with their fellow peers who might either not have adequate knowledge or provide incorrect and shoddy information. The youth therefore, sometimes surf the internet to discover and read more and neither of them might be satisfactory. Another possible reason is that they are less informed, less experienced and do not feel very comfortable in accessing reproductive health services. These characteristics have been reported as part of the observable differences between the youths and the older adults in relation to the use of RHS. ${ }^{[2]}$ Open SRH discussions between parents and children was discovered to have positive influence on the youths sexual perceptions and behavior as it is pertinent that the parents convey sexual values and expectations to their children, and there is a further need for parents to be involved in SRH programme to promote its use of SRHS.

The participants found to have utilized the reproductive health services among the youths were quite low in the present study. A total of 148 (34.9\%) responded that they have used the services while $276(65.1 \%)$ indicated that they have not used the services. This is similar to the study by Bukenya ${ }^{[14]}$ in which the utilization of sexual and reproductive health service by young females was about a quarter $(26.63 \%)$; but higher $(21.5 \%)$ than in the study conducted by Justine et al. ${ }^{[15]}$ Reproductive health services that were sought after, were mostly sought in the home of a health worker, and through public health facility such as a health center, clinic or NGO, as well as the drug shops such as pharmacy or chemist. Similarly in an Ethiopian study ${ }^{[16]}$, sources of RHS include health centers, hospitals, health posts, private clinics and non-governmental health facilities. Clearly this is an indication that most youths do not know where to comfortably obtain RHS. It has been reported elsewhere in Ghana ${ }^{[17]}$ that a good number of sexually active youths do not know where to receive contraceptives and STI treatment due to fear, and embarrassment from service providers. It was also observed, that in sub-Saharan African, irrespective of the fact that they face greater sexual health risks; they also face greater challenges in access to reproductive health services, including preventive care. Socio-demographic characteristics such as age, marital status, living pattern and education were significantly associated with knowledge of RHS.

This study revealed that the major reasons for non-use of the RHS services include fear of being seen by parents at the health facility, shyness and lack of awareness. Also based on the perspective of the study group, barriers to the use of RHS found in this study include non-availability of RHS, fear that the health worker will be biased, unfriendly and hostile, being afraid of hospital procedures, being afraid of the side effects of contraceptives and others. This study is consistent with the study conducted by Mbeba et al. ${ }^{[12]}$ that opined that factors such as lack of youth friendly services, gender disparity and unfavorable socio-cultural practices may create barriers to accessing SRHS and rights. Therefore, there is a need to integrate youth friendly services in health facilities and advocate for behavior change. However, these barriers showed significant influence on the level of utilization of reproductive health services among the youths studied in this study. Some of the most obvious reasons why they obtain reproductive health services through areas mentioned include reduced waiting service time affordability of services and confidentiality. Among the reproductive health services used for family planning services include oral pills, the injectable and the barrier method (e.g. condom). This finding is slightly similar to the reported 
common contraceptive use such as injectable, condom and loop. ${ }^{[16]}$ Most used reproductive health services for prevention and treatment of STIs/STDs include Counseling on the $\mathrm{ABC}$ of prevention of STIs/HIV (Abstinence, being faithful and condom use) the HIV counseling and testing and treatment. This is not a surprise considering the level of enlightenment campaigns of HIV/ AIDS in Nigeria.

The views of the youths on how to increase the use of reproductive health services include affordability of the services, making the environment 'spaced enough' for privacy, making the services more attractive and awareness creation. Other factors in their views include confidentiality and maintenance of privacy, provision of affordable products, proper training of RHS providers, accessibility of roads to care centers, provision of adequate equipment and products and provision of adequate staff. Youth's sexual and reproductive health services utilization was significantly associated and higher among those who had discussion on SRH issues with their parents compared to those who did not had discussion. This could be due to open talk with their parents. By doing this, they would have a good understanding and knowledge about SRH services and this can encourage them to use the service. This finding agreed with other studies $[15,18]$ which brought a positive finding on sexual and reproductive health communication as a means of contraceptive awareness.

In conclusion, the study showed that the knowledge and the level of utilization RHS is still low among youths in the study area. Impending factors of poor utilization by the youths included poor environment, lack of privacy, fear of the elderly, poor attitude of some of the health workers, lack of accessible roads, poor availability of equipment and product supplies, and others. There is need for all stake holders in the health sector to reach a consensus and do an advocacy with the involvement of the youths. The essence of this is to sensitize the public on the importance of youth reproductive health services and strengthen the idea of youth friendly reproductive health services.

\section{Acknowledgement: None}

\section{Conflict of Interest: None}

\section{Source of Funding: None}

\section{Ethical Approval: Approved}

\section{REFERENCES}

1. Eremutha F, Veronica CG. Barriers Limiting Youth Access to Reproductive Health Services by Primary Health Care Facilities in Nigeria. Universal Journal of Public Health. 2019; 7(1): 36-43.

2. Kerbo AA, Tefera TB, Kuti KA, Nur RA. Youth Friendly Sexual and Reproductive Health Services Utilization and Associated Factors in Bale Zone of Ethopia: A Community Based Cross Sectorial Study. Journal Women's Health Reproductive Medicine. 2018; 2(1): 11.

3. USAID. High Impact Practices: AdolescentFriendly Contraceptive Services: Mainstreaming Adolescent- Friendly Elements into Contraceptive Services. USAID. 2015.

4. UNFPA. Adolescent Fact Sheet. The power of 1.8 Billion: Adolescents, Youth and the Transformation of the future Youth in Subsaharan African: UNFPA. 2014.

5. Ojong I, Akpan M, Alasia MO, Nlumanze F. A comparative study on reproductive health awareness among urban and rural secondary school students in Cross River State, Nigeria. Journal of Research in Nursing and Midwifery. 2014; 3(1).21-25.

6. Uka VK. Consumer's and provider's perspective regarding youth reproductive health services in Calabar South Local Government Area of Cross River State Nigeria (Unpublished). 2016.

7. Barot A, Malarcher S. Removing barriers to adolescents' access to contraceptive information and services. Studies in Family Planning. 2010; 41(2): 117-124.

8. Spettel J. The Importance of reproductive Health. 2015; Available at: https://medicalservices.nph.org/2015/05/16/t 
he-importance-of-reproductive-health

[Retrieved July 16, 2020]

9. Country Meters. Nigeria population. Nigeria population clock. 2016; Available at http://countrymeters.infor/en/Nigeria

[Retrieved June 1, 2020]

10. Makinwa-Adebusoye P. Hidden: A profile of married adolescents in Northern Nigeria. 2016; Available at: http://www.actionhealthinc.org/publictions/ docs/hidden.pdf [Retrieved: June 12020$].$

11. Kiran B. Perceived Sexual and reproductive Health needs and Service Utilization among Higher Secondary School Students in Urban Nepal. AM J Public Health Res. 2015; 3(2):36-45

12. Mbeba PM, Nkuye MS, Magembe GE, Yothan WL, Mellan AO, Mkuwa SB. Barriers to sexual and reproductive health services and rights among young people in Mtwara district, Tazania: a qualitative study. The plan African Medical Journal. 2012; 13(1): 23-26.

13. Mngadi PT, Faxelid E, Zawane IT, RansjoArvidson AB. Health providers' perception of adolescent sexual and reproductive health care in Switzerland. International Nursing Review. 2018; 55(2): 111-118.

14. Bukenya JN, Mulogo E, Kibira SP, Muhumuza C, Atuyambe L. Health Facilities' Readiness to Provide Friendly Reproductive Health Services to Young People Aged 10-24 years. Glob J Reprod Med. 2017; 2(3): 55-58.
15. Justine NB, Edgar M, Simon PSK, Christine M, Lynn MA. Health Facilities' Readiness to Provide Friendly Reproductive Health Services to Young People Aged 10-24 years. Glob J Reprod Med. 2017; 2(3): 8589.

16. Birhanu Z, Kora T, Jabana GM. Sexual and Reproductive Health Services use, perceptions and barriers among young people in Southwest Oromia, Ethiopia. Ethipioian Journal of Health Sciences. 2017; 28(1): 37-48.

17. Seth C, Appiah Y. Balancing Youth Friendliness of sexual and reproductive health service delivery and service utilization among Ghanaian youth. International Nursing Review. 2014; 59(8): 78-83.

18. Godia PM, Olenja JM, Lavussa JA, Quinney D, Hoffman JJ, Van Den B. Sexual Reproductive Health Service Provision to Young People in Kenya Health Service Providers Experiences. BMC Health Services Research. 2013; 13:476.

How to cite this article: Onyeneke, J.U., Ibebuike, J., Vincent, C.C.N. et.al. Utilization of reproductive health services among youths in Owerri, Southeastern Nigeria. International Journal of Science \& Healthcare Research. 2021; 6(3): 54-62. DOI: https://doi.org/10. 52403/ijshr.20210710 